\title{
LIFE MATTERS: ACKNOWLEDGING VICTIM RESISTANCE AND THE POWER OF SOCIAL RESPONSES
}

Welcome to this special edition of the International Journal of Child, Youth and Family Studies. We are delighted to bring you this edition, which focuses on exploring interpersonal violence in its broader context. The situational and sociopolitical context of interpersonal violence includes an understanding of the importance of positive social responses for the victim. The term "social responses" refers to the things family, friends, and professionals do during and after disclosure: these responses can strengthen or undermine the well-being of the person who has experienced violence.

These articles are based on certain assumptions about interpersonal violence. One important assumption is that victims - people who are targeted by violence - are not to blame. Victims of violence resist mistreatment, try to preserve their dignity, and enact responses that maximize their safety and the safety of others, even when there is very little room to maneuver. These articles were adapted from presentations at the Responses to Interpersonal Violence conference held at the University of Montreal in May 2016. This conference was accompanied by a meeting of the International Responses to Interpersonal Violence Network, headed by Margareta Hydén from the University of Linköping in Sweden.

In this issue, we have 11 contributors. The edition begins with an article by conference organizers Elizabeth Fast and Cathy Richardson. This article investigates the topic of victimblaming and presents ways to ensure that perpetrators, not victims, are held accountable for the violence, and that safety can be established. Safety is highly dependent upon networks of community and service provision, often including police, courts, protection orders, women's shelters, supportive friends, and diligent family members. Drawing from response-based analysis, developed by Allan Wade, Linda Coates, Nick Todd, and Shelly Bonnah, the authors discuss the importance of accurate language, studying interaction, and eliciting accounts of responses and resistance.

Moving to Cape Town, the next contribution, by South African researchers Floretta Boonzaier and Taryn van Niekerk, highlights their research on responses to violence victims in two marginalized communities in South Africa, including an analysis of various social systems and structures that either promote or impede safety and justice. In 2012, Floretta Boonzaier and Margareta Hydén organized a network meeting in Stellenboch, South Africa. The research and ideas behind a number of these articles began during that period.

Third, we have an article from the Quebec countryside, in which Philippe Roy, Emilie Duplessis-Brochu, and Gilles Tremblay document and analyse the experiences of farming men and how gender stereotypes are both applied and contested. In the following article, Edward Ou Jin Lee, a professor at the University of Montreal, writes about the experience of migrating to 
Canada. His ongoing research documents the pitfalls of the immigration system, in relation to social justice and human rights, with particular emphasis on the multiple sites of oppression for queer and trans immigrants.

The fifth article, by Elizabeth Fast and Marie-Ève Drouin-Gagné, operationalizes Coates and Wade's four operations of discourse model to analyse how violence and mistreatment remain hidden and unaddressed within the educational system and that teaching about colonial histories is a responsibility that unless addressed becomes akin to being a bystander of violence.

Finally, the last article, "Beauty and the Beast: Misrepresentation and Social Responses in Fairy-tale Romance and Redemption", takes up the idea that many stories and images misrepresent violence and give the false message that girls and women can change violent men. Authors Linda Coates, Shelly Bonnah, and Cathy Richardson discuss particular myths that surface through these representations, such as the idea that if you can just stick it out, the abusive man might become a prince, and that it is the role of the woman or girl to tame her man.

We trust that these articles will be thought-provoking, demonstrate the application of responsebased analysis, and assist us, as members of various societies, to address violence and assist in their recovery those who have been harmed.

Sincerely,

Cathy Richardson and Elizabeth Fast

Editors 